\title{
Study on the Sustainable Planning and High Efficiency Utilization of Rural Areas Based on Ecological-Production-Living Space - A Case Study of Shuihu Village, Hengdong County, China
}

\author{
Zhiyuan Wang ${ }^{1^{*}}$, Kao Zhang ${ }^{1}$, Hanling Yi ${ }^{1}$, Jingtong Lv ${ }^{1}$, Xin $\mathrm{Li}^{1}$, Zeqi Yuan ${ }^{1 *}$ and Komi Bernard Bedra ${ }^{2}$ \\ ${ }^{1}$ School of Architecture, University of South China, Hengyang 421001, China \\ ${ }^{2}$ School of Architecture and Art, Central South University, Changsha 410083, China
}

\begin{abstract}
Rural planning is an important part of territorial spatial planning. The study of rural "Ecologicalproduction-living Space" is the key part in optimizing the land spatial development and improving the spatial planning system, which is significant for the sustainable planning and for high efficiency utilization of rural areas. In this study we take Shuihu village, Hengdong County, China, as a case study. (1) The paper applies the Analytic Hierarchy Process to construct a multi-factor evaluation system of villages "Ecologicalproduction-living Space" for their development and construction, agricultural production conditions and ecological function suitability. Establishing the hierarchy model of rural "Ecological-production-living Space" and affecting weight values to each evaluation factor. (2) Using GIS multi-factor grid, we comprehensively evaluate the village space and identify as well as its dominant function. In the plan, the agricultural production as the leading function and as ecological and living space accounts for $36.25 \%$ of the area of the village field. The ecological production accounted for $51.71 \%$, the development and construction accounts for $9.67 \%$. (3) Apply rural complex concept to guide space usage separately from the production space (production and living space), ecological space (ecological living and ecological production space), living space (living ecology and production space) ecological production and living space, to improve the ecological conservation and energy efficiency of agricultural production, to build ecological agriculture, modern agriculture and liveable idyllic community. Through these above parts, we hope to achieve the sustainable development model of rural area and high efficiency utilization of land resources.
\end{abstract}

\section{Introduction}

With the rapid process of urbanization and industrialization and the rapid growth of urban and rural construction land, cultivated land resources are occupied, ecological spaces are damaged and Environmental Bearing-Capacity resources do not fit the speed of construction land expansion, which lead to problems of the inharmonic development of ecology, production and living space as well as an unreasonable structural layout more and more serious [1-2]. In December 2010, the Main Functional Area Planning of China points out that we should according to the division of different functional regions define the performance appraisal system to optimize land area. In January 2017, National Homeland Plan (2016-2030) requires defining a red line for agricultural spaces and ecological spaces protection, urban living space development construction boundary and permanent basic farmland. The designated work of "Ecological-production-living Space" becomes the primary measure of spatial optimization of land; in
November 2018, the Strategy of Rural Rejuvenating (2018-2022) clearly points out that priority development of agriculture, rural areas, deeply implement the "Agriculture Peasant and Countryside" work and promote the ecological, the production and the revitalization of peasants' living, which are decisions and arrangements to further optimize "Ecological-production-living Space" planning layout of rural areas and the coordination of production living and ecology.

Ecological-production-living Space is "ProductionEcology-Living" space. Among them production space is the dominant function area of providing agricultural product, industrial product and service product, which is the foundation of satisfying the human's material requirements, existence and development. Ecology space is the dominant function area of providing ecological service and ecological safeguard, which is the key of coordinating relationship between land and population, protecting ecosystem and achieving the sustainable development of the area [3-4]. Living space is the dominant function area of providing human residence, consumption, amusement and so on, which is the support

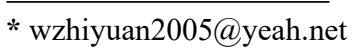


of human living. About "Ecological-production-living Space" planning, scholars performed related researches mainly on the basic connotation and structural system of "Ecological-production-living Space" [5], identification and classification of function of "Ecological-productionliving" [6-7], land use classification and system construction of "Ecological-production-living" [8], optimized layout of "Ecological-production-living Space" [9-10] and pattern succession of "Ecological-productionliving Space" [11] etc. In aspect of research scale dimensions, they not only research the "Ecologicalproduction-living" function of country, province, and city group etc. in macroscale and land use classification by the main functional area [12-13], but also research the "Ecological-production-living Space" demarcation in city territory or county area mesoscale [14-15] and spatialtemporal feature and pattern change of "Ecologicalproduction-living Space" in rural micro scale [16-17]. The research on the sustainable planning pays much attention to Macro-Regional and medium-scale urban while pays relatively less attention to micro scale like county area [18-19]. However, in China the rural space accounts for over $94 \%$ of land areas [20]. We can't ignore the sustainable development of rural space [21]. Taking Shuihu village, Hengyang county in China as object in this paper, we research the planning of "Ecologicalproduction-living Space", further determine its use patterns, refine the research scale of "Ecologicalproduction-living Space" and fill up the theoretical gaps of the planning and evaluation system of "Ecologicalproduction-living Space", which is significant for the sustainable planning and high efficiency utilization of rural space.

\section{Research Area, Methods and Data Sources}

\subsection{Research Area}

Shuihu village is located in the northwest of Wuji town, Hengdong county, Hunan province, China (Figure 1a), 2 kilometres away from Hengdong county, with good geographical advantages. The village has the typical rural space characteristics in southern Hunan. The terrain is dominated by plain and farmland, backed by mountains in the north and rivers in the south (Figure 1b). The total land area of the village is 285.47 hectares with a total population of 2760 people. Shuihu village belongs to the sub-tropical continental monsoon climate where annual average temperature is $17.7^{\circ} \mathrm{C}$. The annual average sunshine hours is $1812 \mathrm{~h}$. Rainfalls are abundant, seasons are distinctive, water is sufficient and the soil is fertile, it is very suitable for crop growth and is given priority to with the traditional farming. Food crops are given priority to. Rice and economic crops are given priority to Huang Gong pepper and medicinal herbs cultivation, among them Huanggong pepper is the Chinese geographical indications of agricultural products.

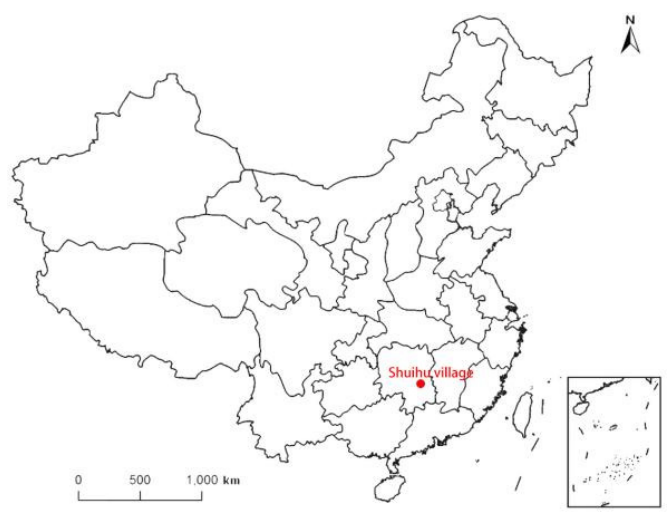

(a)

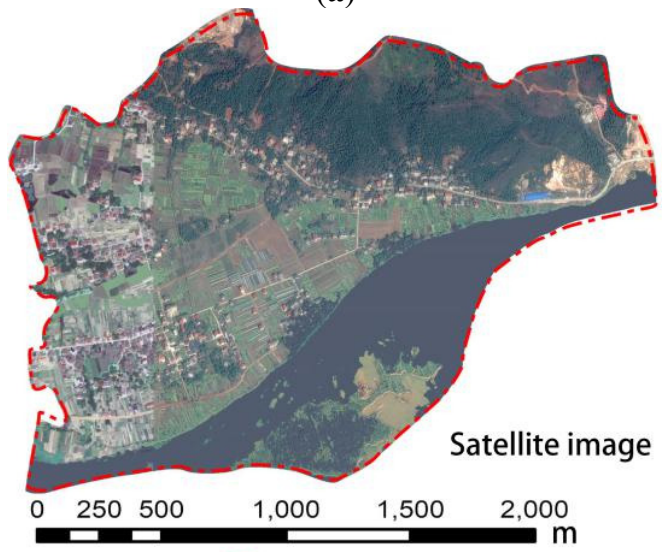

(b)

Figure 1. Geographical location and satellite image of Shuihu Village.

\subsection{Research Methods}

\subsubsection{Analytic Hierarchy Process}

Analytic hierarchy process (AHP) is a systematic and hierarchical analysis method combining qualitative and quantitative [22]. The study uses the Analytic Hierarchy Process to construct the evaluation system of "Ecologicalproduction-living Space". The basic steps of AHP are as follows:

(1) Establish the hierarchical structure model. On the basis of deep analysis of practical problems, the related factors are decomposed into levels of target, criterion and scheme according to different attributes from top to bottom. The factors at the same level are subordinate to the factors at the upper level or have an impact on the factors at the upper level and at the same time dominate the factors at the next level or are affected by the factors at the lower level. In general when there are more than 9 criteria, we should further decompose the sub-criteria layer.

(2) Construct pair comparison verdict matrix where A, $u_{i} 、 u_{j}(i, j=1,2, \ldots, n)$ represent factors, $u_{i j}$ represents the numeric values of the relative importance of ui to $u_{j}$, and the judgment matrix $P$ of $A-U$ is constituted by $u_{i j}$.

$$
P=\left[\begin{array}{cccc}
u_{11} & u_{12} & \ldots & u_{1 n} \\
u_{21} & u_{22} & \ldots & u_{2 n} \\
\ldots & \ldots & \ldots & \ldots \\
u_{n 1} & u_{n 2} & \ldots & u_{n n}
\end{array}\right]
$$


(3) Calculate the weight vector. The proportion index in the evaluation is determined according to its importance relatively to the previous evaluation. Through the judgment matrix, we obtain the characteristic vector $\mathrm{W}$ corresponding to the largest relative eigenvalue $\lambda \max$. The formula is: $\mathrm{PW}=\lambda \operatorname{maxW}$. The characteristic vector $\mathrm{W}$ is normalized, which is the order of importance of each evaluation factor, as well, the weight distribution.

(4) Consistency check. Judge whether the weight distribution obtained above is reasonable and use the check formula:

$$
\begin{aligned}
& C I=\frac{\lambda_{\max }-n}{n-1} . \\
& C R=\frac{C I}{R I} .
\end{aligned}
$$

At formula: $\mathrm{CI}$ is the general consistency index of verdict matrix; $\mathrm{RI}$ is the mean random consistency index of verdict matrix; $\mathrm{CR}$ is random coincidence coefficient of verdict matrix.

When $\mathrm{CR}$ of verdict matrix $\mathrm{P}<0.1$ or $\lambda \max =\mathrm{n}, \mathrm{CI}=0$, we consist that $\mathrm{P}$ has a satisfying consistency or we have to adjust the elements in $\mathrm{P}$ to make it have a satisfying consistency.

\subsubsection{GIS Comprehensive Evaluation}

GIS comprehensive evaluation is using GIS software to process and analyse the total value of multiple geographical elements impact factors in a certain scale by a linear weighting function and comparing the size of the sum value to plan the dominant type of spatial function. The calculation formula of the model is:

$$
F=\sum_{i=0}^{n} F_{i} W_{i} \times 100 .
$$

At formula: $\mathrm{F}$ is contribution score of the dominant function of space; Fi is the single contribution score of evaluation factor i; Wi is the weight of evaluation factor; $\mathrm{n}$ is the number of geographical elements impact factors.

On the basis of the single factor evaluation by GIS, the multi-factor grid computing is carried out to comprehensively evaluate the composite space, so as to obtain the appropriateness of the utilization of village spaces, identify the dominant and secondary functions of land use [23] and plan the "Ecological-production-living Space" of the village.

\subsubsection{Rural Complex Planning}

Rural complex planning is a comprehensive rural development model integrating modem agriculture, leisure tourism, and rural communities. Its purpose is to help agricultural development by tourism and promote a sustainable development pattern of Three Industries Integration, which plays an important role in invigorating "Ecological-production-living Space" [24-25].According to the analysis of "Ecological-production-living Space" which was recognized and delimited by the present situation of village land resources function, we further plan the village "Ecological-production-living Space" for agriculture and forestry, for the processing industry and the leisure travel service industry. We also propose industrial development strategy and combined with modern ecological agriculture, leisure tourism, rural community integration concept to explore the rural comprehensive development pattern.

\subsection{Data Sources}

The basic data mainly comes from the land use data provided by the local government (image data and statistical data). DEM data and land use visual interpretation are from Landsat8LI data. The DEM data are $30 \mathrm{~m}$ resolution of GDEMDEM data, including Google satellite map in TIF format downloaded in 2018 from Google earth. Landsat8LI data has a total of 11 band and we select the B3 B5 and B7 bands. The statistical data is from Hunan province statistical yearbook and Hengyang city statistical yearbook.

\section{Construction of "Ecological- production-living Space" Evaluation System Based on AHP}

Combined with the principle of the main functional area classification [26], we select multiple factors from the suitability of construction, agricultural production function and ecology function to construct the suitability evaluation system of village "Ecological-productionliving Space". In order to improve the accuracy and reduce mistakes, the determination of evaluation factors applies the Analytic Hierarchy Process to construct the system layer and all the indicator layers.

\subsection{The Evaluation Index of Development and Construction Suitability}

The construction of the system layer is based on the development and the construction suitability of rural spaces. Transportation accessibility, topography and geomorphology, living conditions, public service and social security indicator layers are selected and their ratings further refined to construct the evaluation system. The quantitative description and the evaluation of the classification index system can synthetically judge whether the village land is suitable for construction.

\subsection{The Evaluation Index of Agricultural Production Suitability}

The development potential for agricultural production is affected by the soil, the hydrological conditions and the socio-economic conditions etc. Therefore, when evaluating the suitability for agricultural production we mainly consider the convenience of agricultural development and the applicability for land production.

\subsection{The Evaluation Index of Ecological Function Suitability}

The existing research used the ecological sensitivity analysis, ecological security pattern and ecological 
service value to balance the land ecological functions. Since the research area is at the village level, considering the environmental characteristics of the village and the availability of basic data, we used ecological security pattern and ecological sensitivity to interpret the ecological functions of the land.

\subsection{The Construction and Weight Determination of the Multi-factor Evaluation System of Composite Space}

The software yaahp was used to construct the hierarchical analysis model of "Ecological-production-living Space" planning, to establish the verdict matrix, to calculate the factor weights of the middle layer and the alternative plan, to verify whether their consistency is 0 , and finally to obtain the weight value of each evaluation factor.

\section{Sustainable Planning of "Ecological- production-living Space" Based on GIS}

According to the degree of suitability, each evaluation index is described quantitatively, the three kinds of evaluation indexes are unified to $5,4,3,2,1$ score to determine five grades: the most suitable, highly suitable, moderately suitable, lowly suitable and unsuitable. Then a single factor analysis is done for each evaluation index using GIS. According to the index weights for multifactor grid computing, we get the suitability of the village space, identifythe dominant and secondary functions for the planning of the village.

\subsection{Suitability Evaluation of Development and Construction}

(1) The evaluation of transportation accessibility

The transportation accessibility and the current roads of the village (village road and county road) are combined on the base map and the road distance is divided according to the per capita walking speed of $50-100 \mathrm{~m} / \mathrm{min}$. Using GIS multi-buffer analysis and re-classification, we determine, weigh and divide grades to get the distance from the village road (Figure 2a), the distance from county roads (Figure $2 b$ ), and the road network density (Figure 2c).

(2) The evaluation of topography and geomorphology

The elevation directly reflects the local temperature, the oxygen content, and the slopes affect the village construction projects making them difficult. Therefore, the grading evaluation of the land topographic and the geomorphic conditions (elevation in Figure 2d) and slope in Figure 2e) can effectively show the suitable plots for village construction.

(3) The evaluation of living conditions

In terms of the radius of influence, the distance from forest areas and industrial areas, and the dispersion degree of residential areas, the living conditions of land is evaluated. Many villages are developed along the waters. The radius of influence refers to the distance to the pits or canals or rivers (Figure 2f), which is the key factor affecting the construction of the village. Comparing the distance of the land to the industrial area (Figure $2 \mathrm{~g}$ ) and the forest area (Figure $2 \mathrm{~h}$ ), the merits of the village development environmental quality can be concluded. The dispersion degree of residential areas largely determines the atmosphere of village construction (Figure $2 i)$. Using the grid units one can generate statistics on the dispersion degree of rural residential areas.

(4) The evaluation of public service and social security

We select the service radius of educational basic facilities, commercial financial facilities and medical and health institution to illustrate the importance of public service and social security to the development of villages. As to the current facilities of the village, the suitability for development and construction is classified by GIS elements turning point and multi buffer zone analysis(Figure 2j,k,l). 


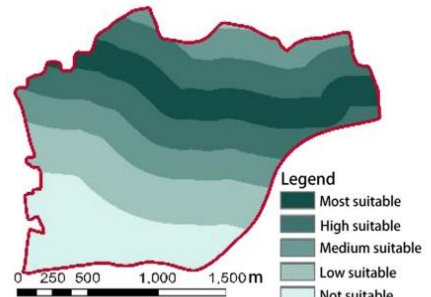

(a)

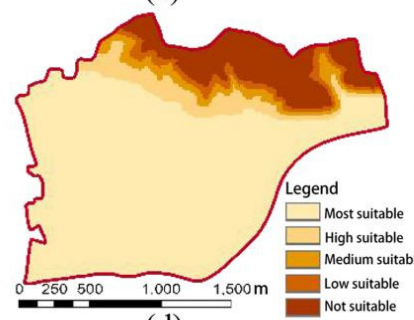

(d)

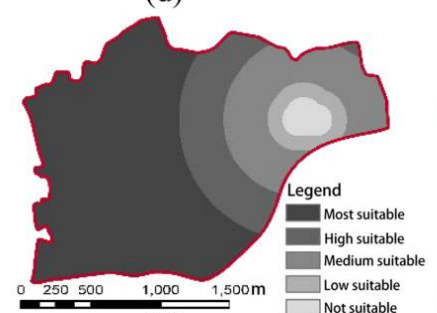

(g)

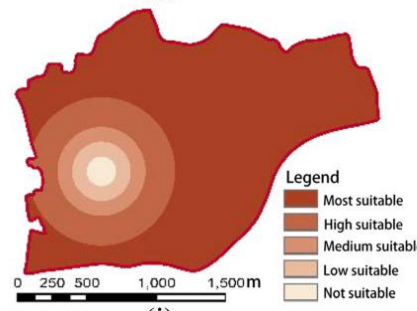

(j)

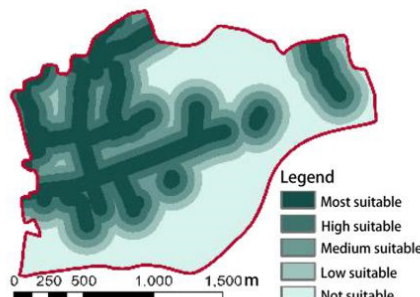

(b)

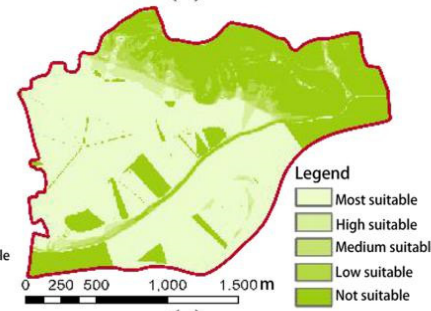

(e)

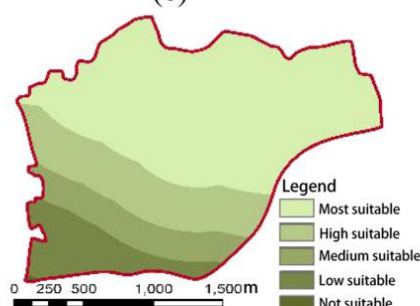

(h)

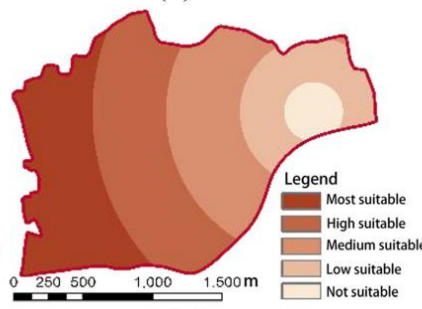

(k)

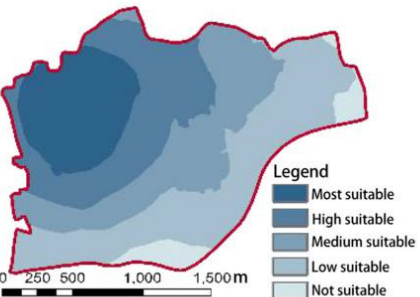

(c)

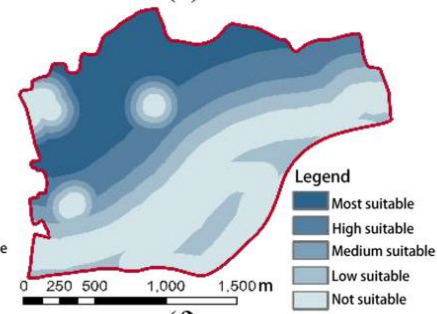

(f)

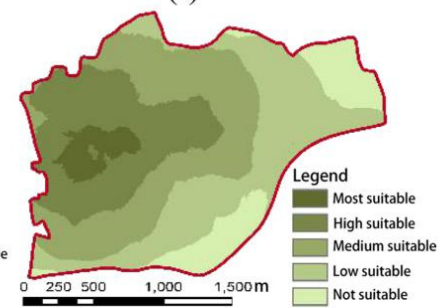

(i)

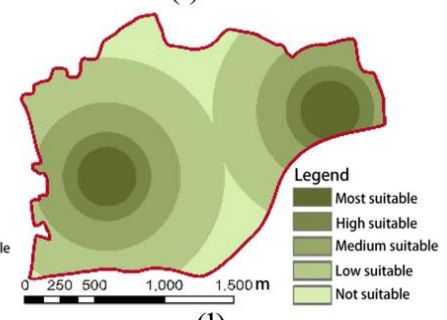

(1)

Figure 2. Suitability evaluation of village development and construction.

\subsection{Suitability Evaluation of Agricultural Production}

(1) The evaluation of agricultural development convenience

The distance from agricultural lands to village settlements and main roads reflects the aggregation degree of labor resources and the convenience of transportation, which directly affects the agricultural production and development. The closer the agricultural land is to the village settlements and the main roads, the more abundant and convenient the manpower and transportation are, which can effectively reduce the production cost and improve its efficiency (Figure 3a, 3b).
(2) The evaluation of utilization suitability for production

Agricultural crops are more easily affected by topographic conditions, and contour ploughing greatly affects the suitability of agricultural production. In other words, the steeper the slope, the more difficult the agricultural tillage; the smaller the slope, the more convenient the agricultural tillage (Figure $3 \mathrm{c}$ ). The slope direction, to a certain extent, determines whether the tillage is on the sunny side and affects the growth and the tillage output quality. The south oriented slopes and the flat slopes are considered as the most suitable, the southwest and southeast slope are classified as highly suitable, the east and west slope as moderately suitable, the northeast and northwest slope as lowly suitable, and the north slope as not suitable (Figure 3d). 


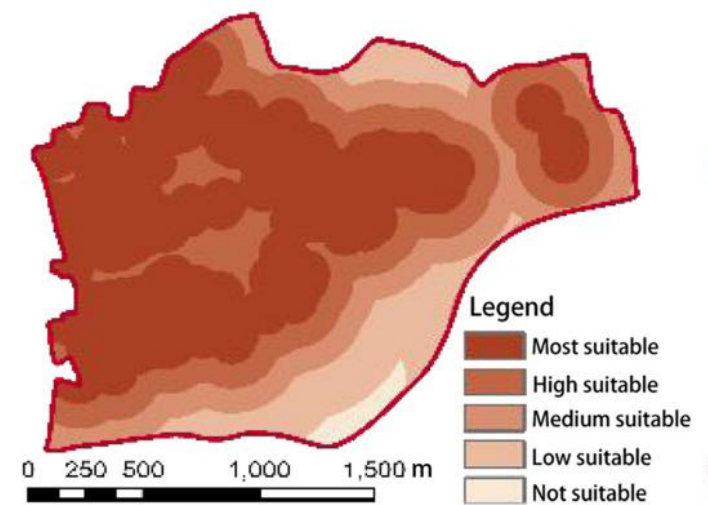

(a)

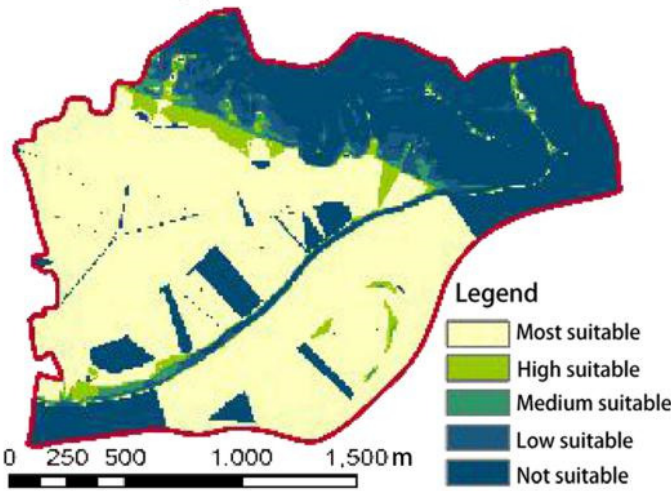

(c)

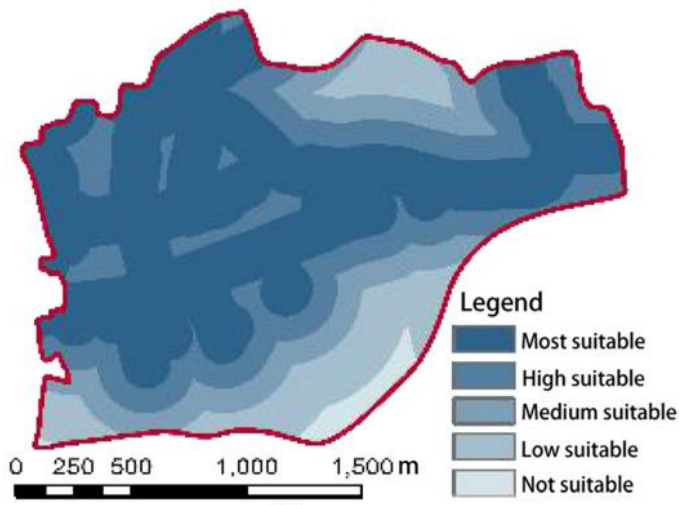

(b)

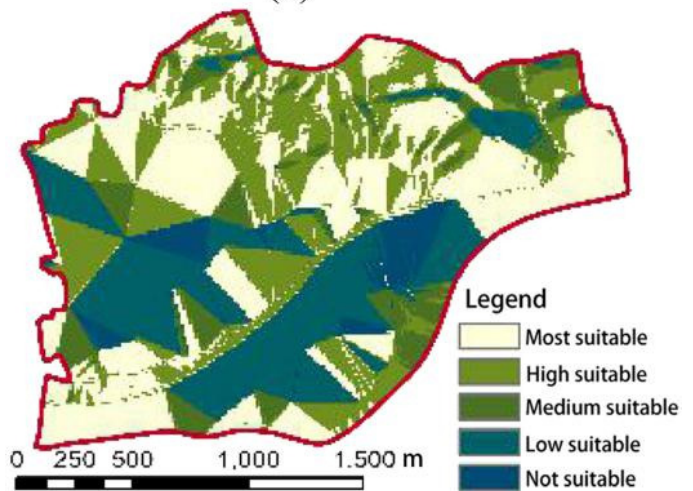

(d)

Figure 3. Suitability evaluation of village agricultural production.

\subsection{Suitability Evaluation of Ecological Function}

(1) The evaluation of ecological security pattern

Since the village is close to the river, the river has potential flood threat. Considering rainwater safety is an evaluation element of ecological security pattern, the suitability is divided by the distance of the village from the river. Closer to the river, greater the threat to the rainwater safety and lower the ecological suitability (Figure 4a). The reservoir ponds are of great significance to the security pattern of the water sources of the village. The distance from the water source is an important indicator affecting the water source security of the village, and it is selected as the evaluation factor. The closer the distance to the water source, the higher the ecological suitability (Figure 4b).
(2) The analysis of ecological sensitivity

The analysis of the ecological sensitivity selected two factors, the typical district of the current land use and vegetation of comprehensive evaluation. According to the typical district of current land use of village, we judge whether the block has ecological suitability. The ecological suitability is water area, forest land, grassland, cultivated land and residential area from high to low (Figure 4c). The ecological suitability of vegetation was determined according to its ecological sensitivity and ecological service value. Highly-sensitive vegetation such as jungle land and beach wetland is the area with high ecological function suitability, while relatively lowsensitive vegetation such as garden land and savanna is the area with low ecological function suitability (Figure 4d). 


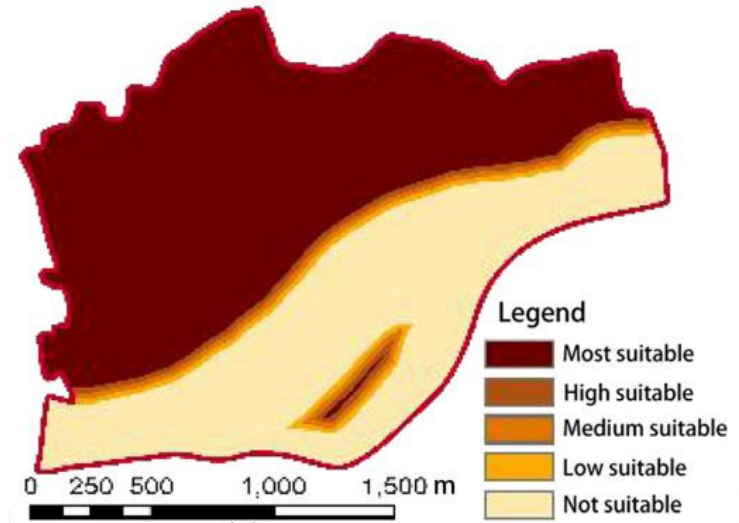

(a)

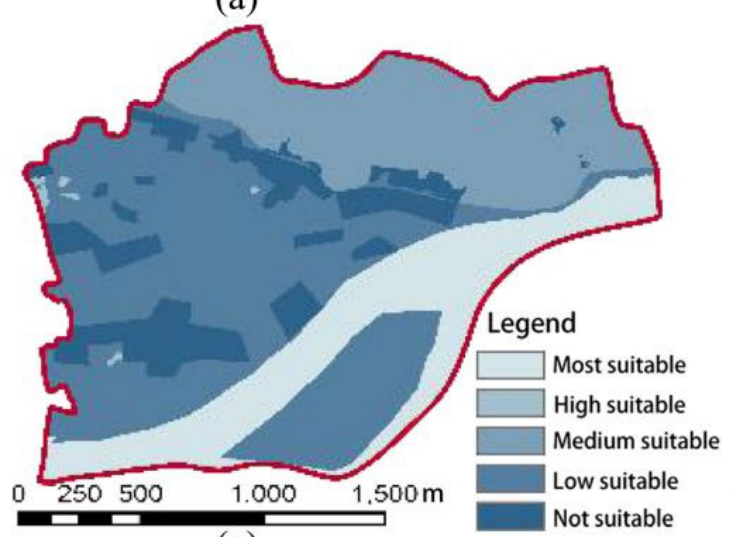

(c)

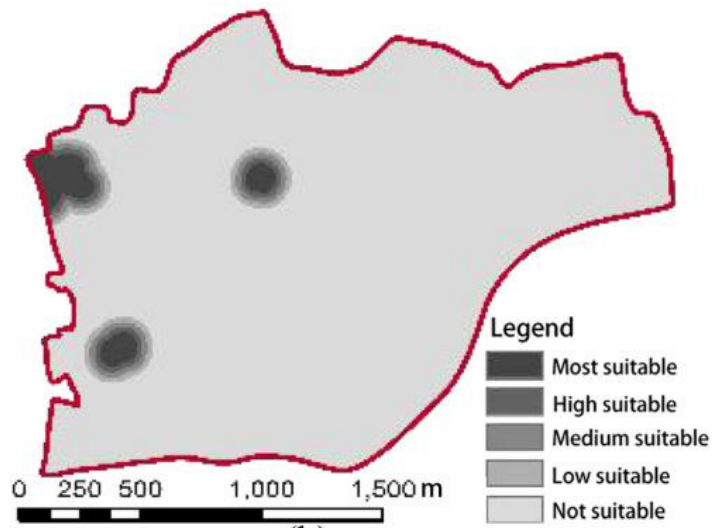

(b)

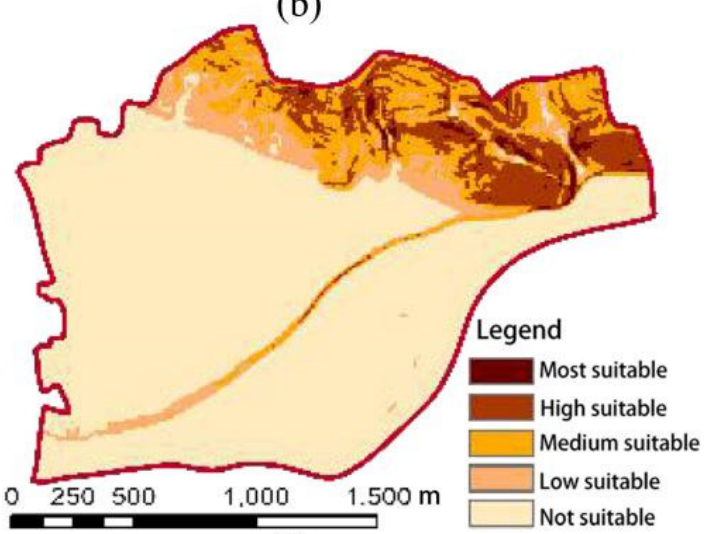

(d)

Figure 4. Suitability evaluation of village ecological function.

\subsection{Sustainable Planning of "Ecological- production-living Space" in Villages}

As the functions of "Ecological-production-living Spaces" are nested with each other, the composite space in "Ecological-production-living Spaces" is subdivided into 7 categories: production ecology, production living, ecological production, ecological living, living production, living ecology and ecological-productionliving space. When the suitability level is most suitable, high suitable and medium suitable, the most suitable level is considered as the main function, followed by the secondary function of the village. If all three index grades are the most suitable possible, then the space is defined as the production-living-ecology space. When the three grade indexes are identical, the space is divided according to the principle that ecological function takes precedence over agricultural production function and agricultural production function takes precedence over village development and construction functions. If the suitability level of the three types of functions is low suitability or unsuitability, the ecological function will be selected as one of the functions, and the surplus according to the principle that agricultural production function takes precedence over the development and construction function.

Comprehensive evaluation of space utilization suitability (Figure 5a, b, c), the results of spatial overlay analysis based on GIS are as follows: the production ecology and production living space of agricultural production as the leading function accounted for $36.25 \%$ of the area of the village, the ecological production and ecological living of ecological function as the leading function accounted for $51.71 \%$ of the area of the village, the living production and living ecology space of development and construction as the leading function accounted for $9.67 \%$ of the area of the village, "Ecological-production-living Space" which is appropriated to all the three kinds of functional suitability accounted for $2.37 \%$ of the area of the village (Figure $5 \mathrm{~d}$ ). 


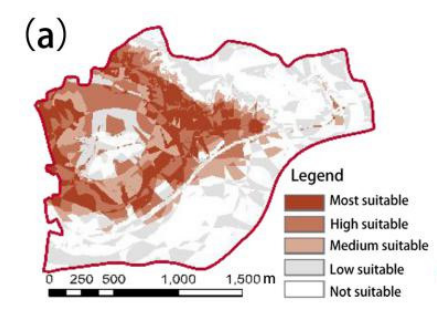

(b)

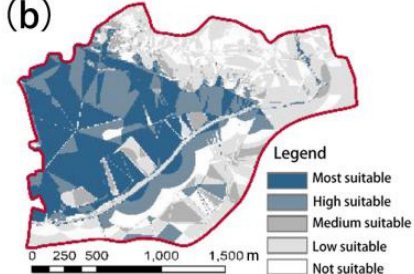

(c)

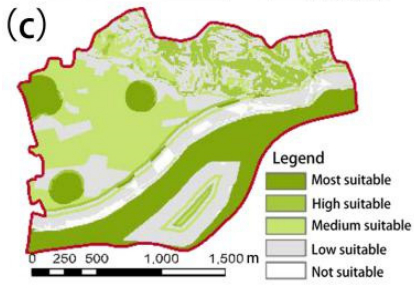

(d)

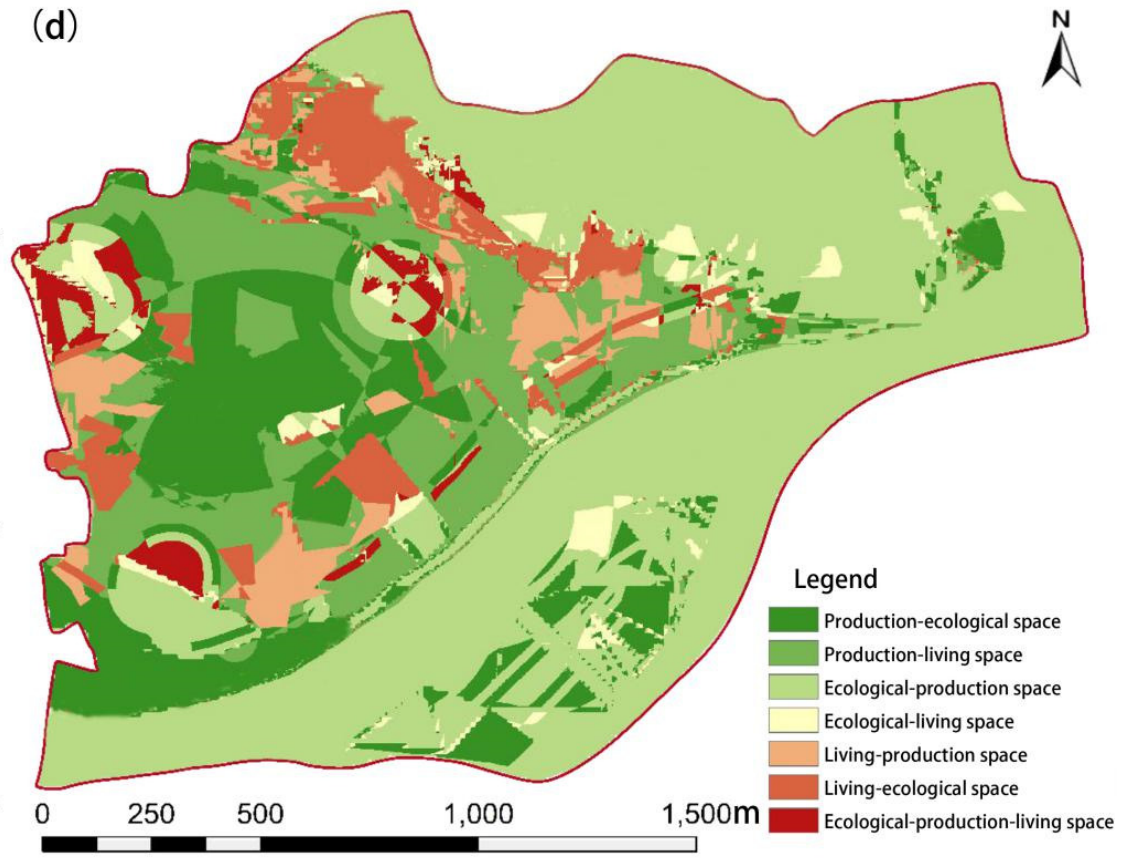

Figure 5. Sustainable planning of village "Ecological-production-living Space" based on GIS suitability evaluation.

\section{Efficient Use of "Ecological- production-living Space" Based on Rural Complex}

\subsection{Thinking of Planning and Utilization}

Focusing on agriculture, improving the energy efficiency of agricultural production, building ecological agriculture, modern agriculture and liveable idyllic community, and improving tourism necessary services are the core goals of meeting the requirements in rural areas for "industrial prosperity, ecological livability, and life prosperity ". According to the planning of village composite space "Ecological-production-living Space", the research regionalizes the leading function, and uses the rural complex concept and guides the space usage respectively from the production space (production living and production ecological space), ecological space (ecological living, ecological production space), living space (living ecological and living production space), so as to achieve the efficient use of land resources.

\subsection{Production Space}

From the distribution pattern of "Ecological-productionliving Space" in the village area, the production space is mainly concentrated in the western part of the village and the Hexin island area, including the most part of farmland and a few village residential areas. According to the distribution of local crop resources, the ecological production space has been transformed from traditional agriculture to large-scale agriculture, and "two parks and two zones" have been set. Through the introduction of modern production cooperation model, the "two parks" are planned for the Huanggong pepper demonstration park and for Chinese medicine planting demonstration. The "two zones", namely modern ecological farmland area, agricultural product processing area, which promote the concentration of cultivated land resources and is conducive to the protection of cultivated lands. The production living space is located around the residential land of the village, which is dominated by recreational activities, providing sightseeing services of agriculture and experience of pastoral life, and extending the agricultural industry chain.

\subsection{Ecological Space}

The ecological space includes most of the forest land in the north of the village and the waters in the village area. The ecological elements are concentrated into a block, which plays an important role in supporting the functional structure of the village space. The purpose of its planning and utilization is to protect the integrity and the ecology of the pastoral scenery under for a sustainable development. Planning the northern ecological woodland reserve area is the foundation of the ecological protection. It is determined that the riverside in the southwest of the village is an ecological breeding garden and an ecological picking garden. Taking rural tourism as the guide to ensure the benefits of ecological resources landscape, meanwhile give play to the better economies of scale, ensure the income of villagers and meet the needs of rural residents for rich life.

\subsection{Living Space}

The Living space is mainly the current villagers' residential area. Three types of original residential areas for local villagers, country house experience areas and 
tourist villa areas are planned to build a comprehensive rural community with landscape appreciation, recreation and liveability value. We will integrate and adjust rural residential areas, make reasonable planning and site selection for new, relocated and repaired residential areas, and determine the size of rural residential areas in each district, so as to promote "effective governance" and "ecological liveability" of living space.

\subsection{Ecological-production-living Space}

The composite space of ecological production and life is mainly distributed in the vicinity of reservoirs and ponds in the village area, which has high land use value and landscape ecological benefits. It is the convergence and integration area of primary, secondary and tertiary industries. Aiming at the development of rural industry combination in this kind of space, a tourism complex area with recreation as the activity theme is built. According to the cluster distribution, the tourism complex can plan three core areas, namely, rural living community, outdoor picking experience area, parent-child leisure and entertainment area, supporting tourism service facilities and living infrastructure, to create a beautiful countryside that is liveable and suitable for travel (Figure 6).

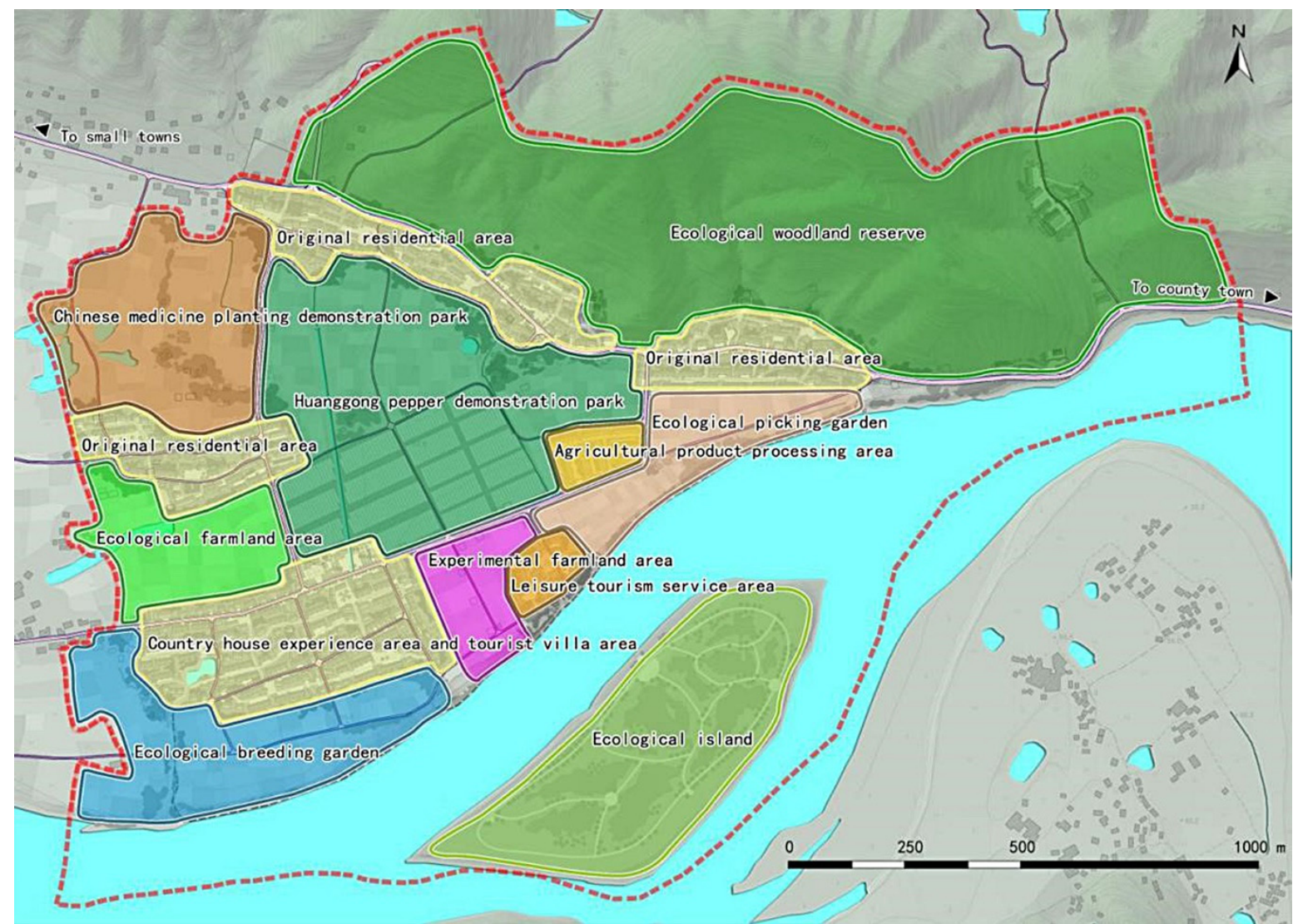

Figure 6. Planning and utilization of village "Ecological-production-living Space" based on rural complex.

\section{Conclusions and Discussion}

This study based on the sustainable development of rural areas, from the perspective of "Ecological-productionliving space", by using GIS multi-factor comprehensive evaluation of the rural spaces suitability, reasonable agricultural production planning (as the leading function of ecological production and living space production), to the ecological as the leading function of ecological production and ecological living space, to the development as the leading function of living production and living ecological space and ecological production space, which is of important guiding significance to improve the optimization for the national spatial planning system in rural areas. Planning the use of rural space based on the concept of rural complex has a strong practical significance to promote the efficient use of rural space, improve the efficiency of land resources and increase farmers' income. Research conclusions include:

(1) Based on the principle of the main functional area regionalization, from three aspects of construction and development suitability, agricultural production suitability and ecological suitability, we select transportation accessibility, topography and geomorphology, living conditions, public service and social security, agricultural development convenience, the applicability of land production, ecological security pattern, ecological sensitivity, etc. as indicators. The multi-factor evaluation system for the suitability of "Ecological-production-living Space" in rural areas was established by the Analytic Hierarchy Process (AHP), and factor weights were determined. Spatial overlay analysis based on GIS was carried on the comprehensive 
evaluation of rural space. The research method has a certain innovation, a strong operability, and can be popularized.

(2) By using GIS multi-factor grid computing, we get the suitability of village space utilization and identify the dominant and secondary functions of the rural space. The results show the agriculture production as the leading function of ecological production and living spaces account for $36.25 \%$ of the total area of the village fields. The ecological production as the leading function of ecological production and living space accounted for $51.71 \%$. The development and construction as the leading function of living production and ecological space accounted for $9.67 \%$. The suitability of the three functions belongs to the more suitable ecological production and living space which accounts for $2.37 \%$ of the area of the village fields.

(3) Applying rural complex concept, the land use is composed by the production space (production living and ecological space), the ecological space (ecological living and production space), living space (living ecology and production space) ecological production and living space, so as to achieve the Sustainable development model of rural area.

\section{The following aspects should be paid attention to in the in-depth study of "Ecological-production-living Space"}

(1) Rural spaces due to the regional differences and differences in land use, and to the difference of the "Ecological-production-living Space" planning from the current land use, cannot be treated as the same, its planning should adjust measures to local conditions, selecting reasonable evaluation factors, considering the coupling between each factor and space of land carrying capacity, soil conditions, resources and environment carrying capacity, landscape fragmentation and other factors to conduct further analysis and form the integrated system framework.

(2) On the micro scale, remote sensing information should be properly combined to carry out data analysis for "Ecological-production-living Space" planning. By summarizing the evolution of the scale and type of "Ecological-production-living Space" over the years, its key influencing factors should be inferred, and the weight of analysis should be summarized to ensure that the evaluation system is scientifically sound.

(3) As the planning system of rural space is not mature yet, it needs to be explored in depth. Theoretical researches are need to build a systematic framework and an "analysis -- planning -- utilization -- control" process, starting from the harmony perspective of "human-earthresource" and making empirical analysis. Other dimensions could also be comprehensively considered.

\section{Funding}

This research was funded by Hunan Philosophy and Social Science Foundation, grant number 18YBQ106;
Education Department Project of Hunan Province, grant number 19B480.

\section{References}

1. Foley, J.A Defries, R, Asner, G.P. et al. Global consequences of land use. Science, 2005, 309, 570574.

2. Bai, X.M. Shi, P.J. Liu, Y.S. Realizing China's urban dream. Nature, 2014, 509, 158-160.

3. Kates, R.W. Clark, W.C. Corell, R. et al. Sustainability science. Science, 2001, 292, 641-642.

4. Costanza, R. D'Arge, R. de Groot, R. et al. The value of the world's ecosystem services and natural capital. Nature, 1997, 387, 253-260.

5. Liu, J.L. Liu, Y.S. Li, Y.R. Classification evaluation and spatial-temporal analysis of "production-livingecological" spaces in China. Acta Geographica Sinica, 2017, 72, 1290-1304.

6. Nelson, E. Modeling multiple eco-system services, biodiversity conservation, commodity production, and tradeoffs at landscape scales. Frontiers in Ecology and the Environment, 2009, 7, 4-11.

7. Liu Y. On the logical structure, check and balance mechanism and development principle of "production-living-ecological space". Social Sciences in Hubei, 2016, 3, 5-9.

8. Cheng, T, Zhao, R, Liang, Y, Production-livingecological space classification and its functional evaluation. Remote Sensing Information, 2018, 33, 114-121.

9. Wang, C, Tang, N, Spatio-temporal characteristics and evolution of rural production-living-ecological space function coupling coordination in Chongqing Municipality. Geographical Research, 2018, 37, 1100-1114.

10. Hu, W.T, Wang, L.G, Shu, M.H. Reflections on delimiting the three basic spaces in the compilation of urban and rural plans. City Planning Review, 2016, 40, 21-26.

11. Liu, D.Q. Ma, X.C. Gong, J. et al. Functional identification and spatiotemporal pattern analysis of production-living-ecological space in watershed scale: A case study of Bailongjiang Watershed in Gansu. Chinese Journal of Ecology, 2018, 37,14901497.

12. Zhang, H.Q, Xu, E.Q. Zhu, H.Y. An ecologicalliving-industrial land classification system and its spatial distribution in China. Resources Science, 2015, 37, 1332-1338.

13. Ma, S.F. Ma, M. Cai, Y.M. et al. Delimitating red line of ecological protection for territorial spatial planning: A case study of Hunan Province. Tropical Geography, 2015, 35, 43-50.

14. Zhu, Y.Y. Yu, B. Zeng, J.X. et al. Spatial optimization from three spaces of production, living and ecology in national restricted zones: A case study of Wufeng 
County in Hubei Province. Economic Geography, 2015, 35, 26-32.

15. Song, M.J. Chen, D.M. Katie W. An RP-MCE-SOP framework for China's county-level "Three-Space" and "Three-Line" planning-An integration of rational planning, Multi-Criteria evaluation, and spatial optimization. Sustainability, 2019, 11, 2997.

16. Zhang, Y.L. LI,X. Sun, S.L. Evaluation and optimization of rural space suitability based on "the Production, Living and Ecological Space Coordination"--Take Beishakou township, the Xiongan New Area as an example. Urban Development Studies, 2019, 26, 116-124.

17. Xi, J.C. Wang, S.K. Zhang, R.Y. Restructuring and optimizing production-living-ecology space in rural settlements: A case study of Gougezhuang Village at Yesanpo tourism attraction in Hebei Province. Journal of Natural Resources, 2016, 31, 425-435.

18. Rudolf,G. Function-analysis and valuation as a tool to assess land use conflicts in planning for sustainable, multifunctional landscapes. Landscape and Urban Planning, 2006, 75, 175-186.

19. Reidsma, P. König, H. Feng, S.Y. et al. Methods and tools for integrated assessment of land use policies on sustainable development in developing countries. Land Use Policy, 2011, 28,604-617.

20. Guangming Daily commentator. Improve rural environment and build beautiful countryside. Guangming Daily, 2018-2-6(2). http://news. gmw.cn/2018-02/06/content_27591798.htm

21. Liu, Y. Yang, W. Leadership and governance tools for village sustainable development in China. Sustainability, 2019, 11, 5553.

22. Forman, E.H. Gass, S.I. The analytic hierarchy process: An exposition. Operations Research, 2001, 49, 469-486.

23. Bennett, E.M. Peterson, G.D. Gordon, L.J. Understanding relationships among multiple ecosystem services. Ecology Letters, 2009, 12, 13941404.

24. Cucari, N. Wankowicz, E. De Falco, S.E. Rural tourism and Albergo Diffuso: A case study for sustainable land-use planning. Land Use Policy, 2019, 82,105-119.

25. Cattaneo, T. Giorgi, E. Ni, M. Landscape, architecture and environmental regeneration: $\mathrm{A}$ research by design approach for inclusive tourism in a rural village in China. Sustainability, 2019, 11, 128.

26. Fan, J. The scientific foundation of Major Function Oriented Zoning in China. Journal of Geographical Sciences, 2007, 62, 339-350.

(C) 2020 by the authors. Submitted for possible open access publication under the terms and conditions of the Creative Commons Attribution (CC BY) license (http://creativecommons.org/licenses/by/4.0/). 